University of Louisville

ThinkIR: The University of Louisville's Institutional Repository

Electronic Theses and Dissertations

$5-2017$

\title{
Using a multi variate pattern analysis (MVPA) approach to decode FMRI responses to fear and anxiety.
}

\author{
Sajjad Torabian Esfahani \\ University of Louisville
}

Follow this and additional works at: https://ir.library.louisville.edu/etd

Part of the Computer Engineering Commons, and the Computer Sciences Commons

\section{Recommended Citation}

Torabian Esfahani, Sajjad, "Using a multi variate pattern analysis (MVPA) approach to decode FMRI responses to fear and anxiety." (2017). Electronic Theses and Dissertations. Paper 2652.

https://doi.org/10.18297/etd/2652

This Master's Thesis is brought to you for free and open access by ThinkIR: The University of Louisville's Institutional Repository. It has been accepted for inclusion in Electronic Theses and Dissertations by an authorized administrator of ThinkIR: The University of Louisville's Institutional Repository. This title appears here courtesy of the author, who has retained all other copyrights. For more information, please contact thinkir@louisville.edu. 


\title{
USING A MULTI VARIATE PATTERN ANALYSIS (MVPA) APPROACH TO DECODE FMRI RESPONSES TO FEAR AND ANXIETY
}

By

\author{
Sajjad Torabian Esfahani \\ B.Sc., University of Tehran, 2015 \\ A Thesis \\ Submitted to the Faculty of the \\ J.B. Speed School of Engineering of the University of Louisville \\ in Partial Fulfillment of the Requirements \\ for the Degree of \\ Master of Science \\ in Computer Science \\ Department of Computer Engineering and Computer Science \\ University of Louisville \\ Louisville, Kentucky
}

May 2017 



\section{USING A MULTI VARIATE PATTERN ANALYSIS (MVPA) APPROACH TO DECODE FMRI RESPONSES TO FEAR AND ANXIETY \\ By \\ Sajjad Torabian Esfahani \\ B.Sc., University of Tehran, 2015 \\ A Thesis Approved on}

April 17, 2017

by the following Thesis Committee:

Dr. Roman Yampolskiy, Director

Dr. Brendan Depue, Co-Director

Dr. Ibrahim Imam 


\title{
ABSTRACT \\ USING A MULTI VARIATE PATTERN ANALYSIS (MVPA) APPROACH TO DECODE FMRI RESPONSES TO FEAR AND ANXIETY
}

\author{
Sajjad Torabian Esfahani
}

April 17, 2017

This study analyzed fMRI responses to fear and anxiety using a Multi Variate Pattern Analysis (MVPA) approach. Compared to conventional univariate methods which only represent regions of activation, MVPA provides us with more detailed patterns of voxels. We successfully found different patterns for fear and anxiety through separate classification attempts in each subject's representational space. Further, we transformed all the individual models into a standard space to do group analysis. Results showed that subjects share a more common fear response. Also, the amygdala and hippocampus areas are more important for differentiating fear than anxiety. 


\section{TABLE OF CONTENTS}

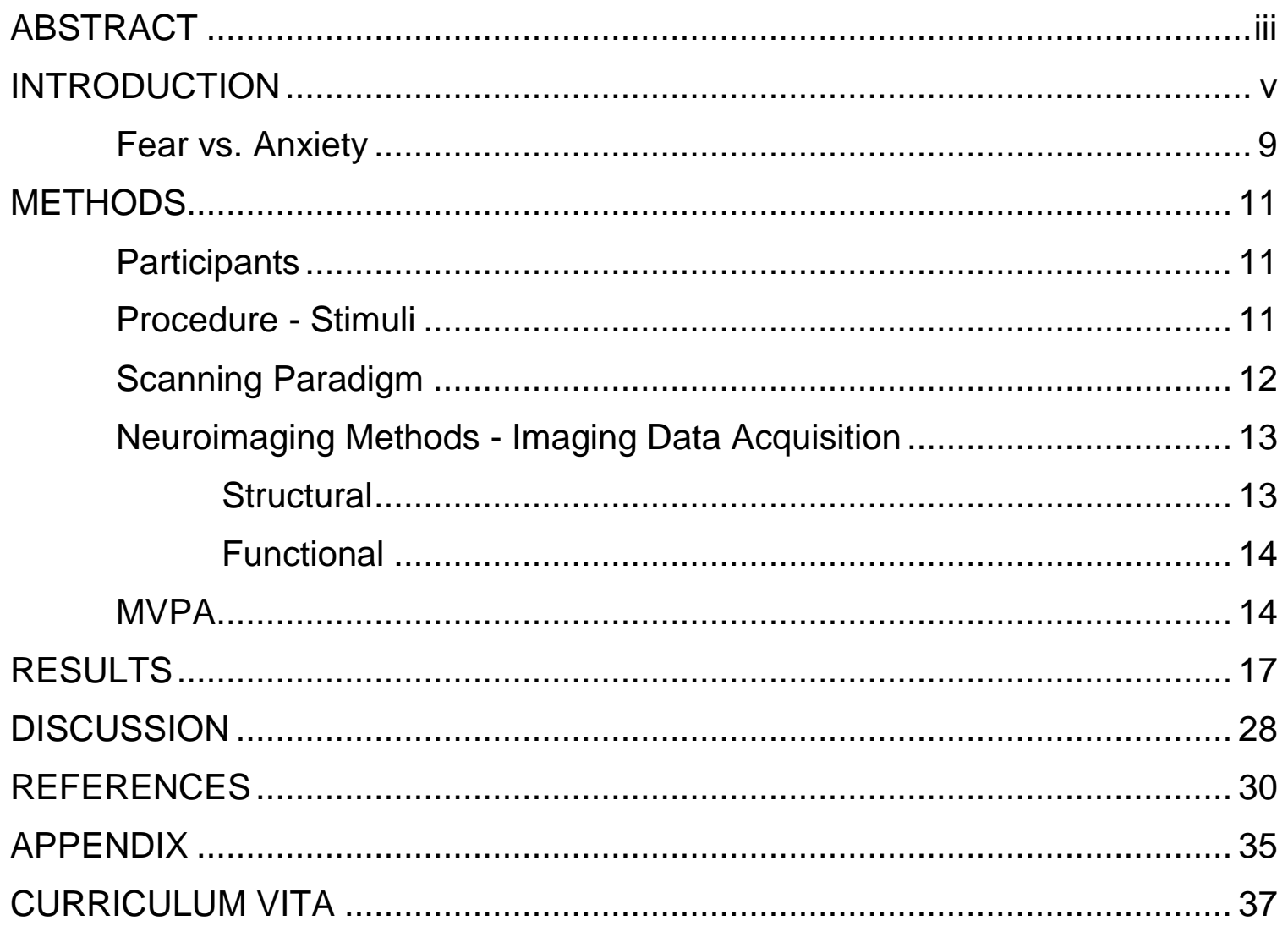




\section{LIST OF FIGURES}

Figure 1: Schematic drawing of dividing the two hemispheres. Labeling the right and left hemispheres only with specific tasks tells too little about their relationship. Adapted from Baars \& Gage (2010)

Figure 2: A single neuron in the basal ganglia. Horizontal bars mark 50

micrometers. Adapted from Baars \& Gage (2010)......................................... 3

Figure 3: Transforming 3D functional volumes into a new configuration with $\mathrm{n}$ (= number of features) dimensions. Each dimension is a voxel's intensity. 5 Figure 4: Independent volumes from category A/B would settle in the vicinity of the previously observed red/blue data point.

Figure 5: Fear vs. neutral (red) and anxiety vs. wait (blue) classification results for all the 20 subjects.

Figure 6: Fear vs. anxiety normalized based on neutral (lime) and based on wait (dark green) classification results for all the 20 subjects.

Figure 7: 3D views of fear vs. neutral (red), anxiety vs. wait (blue), and fear vs. anxiety (green) patterns, shared by at least 8 of the individuals. 23

Figure 8: 3D views of fear vs. neutral (red), anxiety vs. wait (blue), and fear vs. anxiety (green) patterns, shared by at least 10 of the individuals. 24

Figure 9: Ventral views of portions of the patterns from the amygdala (top left), hippocampus (top right), and ventral visual processing stream (bottom). 25 


\section{INTRODUCTION}

MultiVariate Pattern Analysis (MVPA) is a new approach for analyzing functional magnetic resonance imaging (fMRI) data that was presented for the first time in a research article on representations of faces and objects in ventral temporal cortex (Haxby et al., 2001). Although the main idea was introduced by Haxby et al., it was later at Princeton University that the approach took the name Multi-Voxel Pattern Analysis and subsequently Multi-Variate Pattern Analysis (MVPA) in order to show its more general applicability. In contrast to the former univariate analysis which represents regions of activation, MVPA provides us with more detailed and thus more informative patterns of neural responses. These patterns - or regions in case of univariate analysis - appear while being situated in different conditions from attention-demanding states to rest (Vanhaudenhuyse et al., 2010).

Before MVPA was introduced and developed, researchers could only discern activation of regions based on univariate analysis with the general linear model (GLM). These models of cortical organization are able to tell whether or not specific areas are involved in a particular task. A typical tasks' goal would be to find areas in the brain for various parts of the body.

First, it is worth mentioning that the field of neuroscience no longer believes that each brain region is associated with only one task and nothing else. In a study 
by (Kanjlia et al., 2016) as an instance, it was shown that "visual" areas are also involved in mathematical thinking. Below, we can also see the common mistake of using the simple label "Divided - corpus callosum". This would again consider the two hemispheres as separate areas which tells too little about their relationship. We know that the two hemispheres function differently, but clearly communicate with each other. For example, the $\mathrm{LH}$ is known to be dominant in language processing. However, it is shown that the $\mathrm{RH}$ contributes to some aspects of this processing such as comprehension of natural language, as well (Jung-Beeman, 2005).

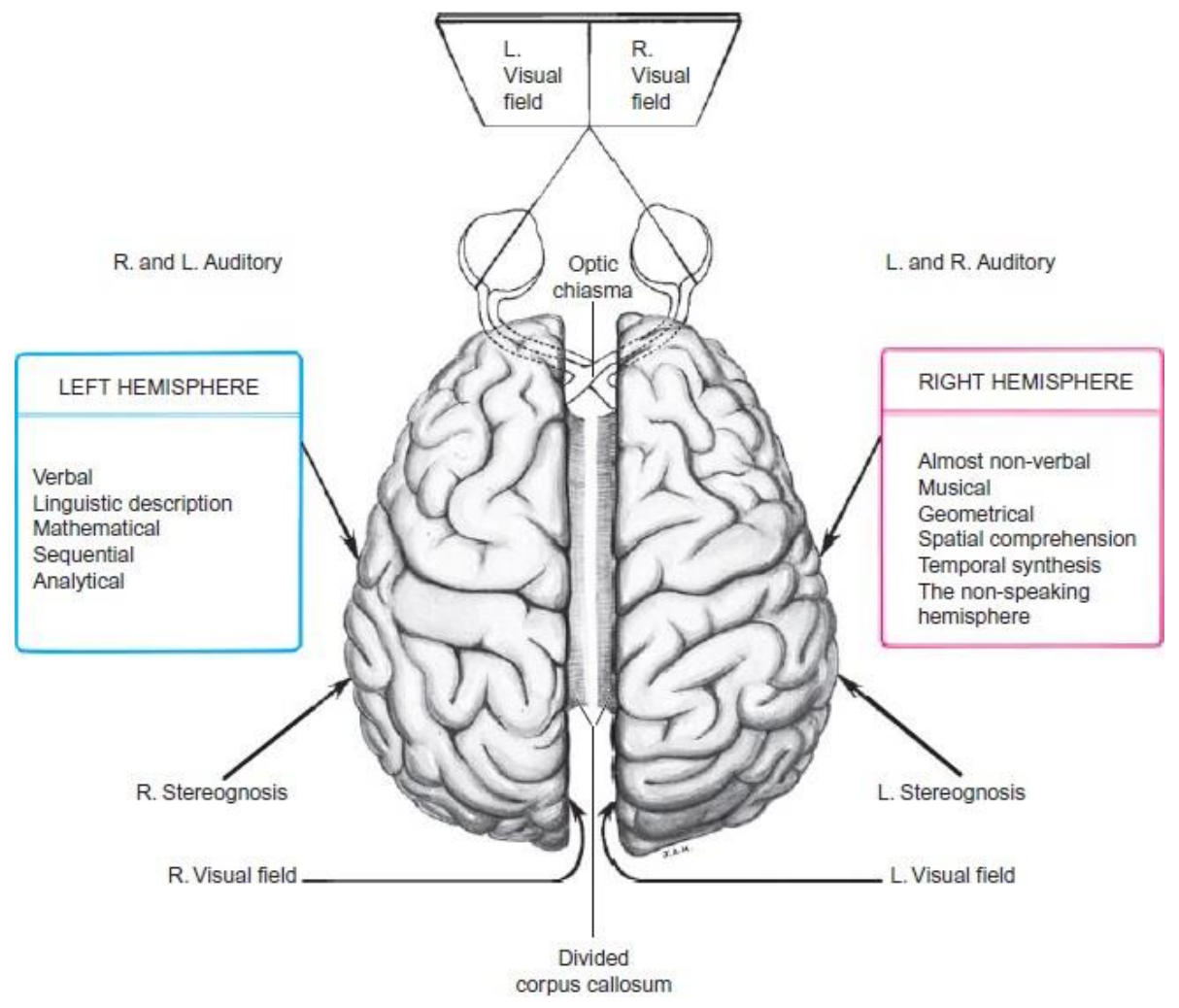

Figure 1: Schematic drawing of dividing the two hemispheres. Labeling the right and left hemispheres only with specific tasks tells too little about their relationship. Adapted from Baars \& Gage (2010)

Second, there are not actual regions that are functioning in different conditions. There are, instead, networks of neurons being activated in response to 
stimuli. But how accurately are we able to capture this neural activity? fMRI uses blood-oxygen-level dependent (BOLD) contrast which is caused by the oxygen demand of active neurons. This is an indirect measurement, and should be coupled with various parameters of neural function to have a better reflection of neural activity (Singh, 2012). Besides, fMRI is limited in both temporal and spatial resolution. A common voxel (the smallest unit of measurement in $\mathrm{fMRI}$ ) size in functional MRI is $3 \mathrm{~mm}^{3}$. Figure 2 depicts a single neuron in the basal ganglia, and the horizontal bars mark 50 micrometers. Comparing the available spatial resolution and the size of a neuron clearly shows how much data we're missing when looking at an fMRI image. There might be thousands of neurons firing with intensity below the threshold that can be captured in a voxel by fMRI. In which case, if the majority of neurons in a voxel are firing and we would get signal from that area. Otherwise, when we're not receiving signal from a voxel, we cannot come to the conclusion that there are no neurons firing.

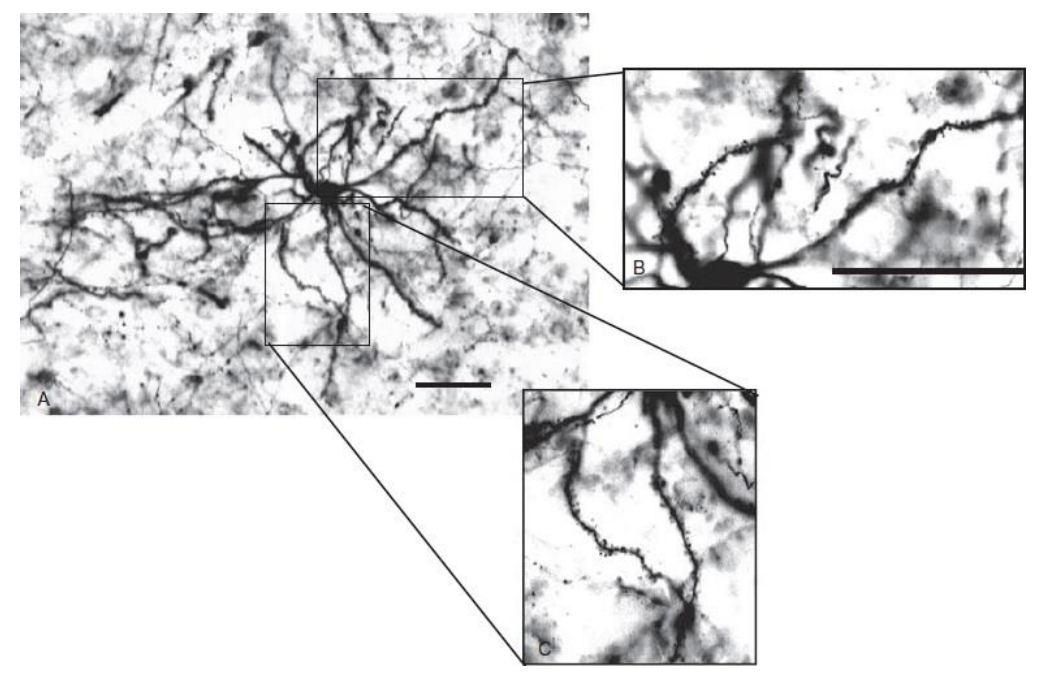

Figure 2: A single neuron in the basal ganglia. Horizontal bars mark 50 micrometers. Adapted from Baars \& Gage (2010) 
Although we're limited in the different ways discussed above, this is the best accuracy that technology is offering now; and with the same scanning resolution, MVPA is a major step towards a more detailed model of cortical organization by examining patterns of voxels instead of general regions of activation.

Regarding the current project, we explain the main idea behind MVPA by considering a simple case of having two stimulus categories A and B (fear and anxiety stimuli in the current experiment). Subjects are shown instances of two categories multiple times, and at the same time, the scanner captures 3D functional volumes (a whole brain representation) of their brains (a total of 340 volumes in this study). Therefore, we will eventually have a set of brain volumes with known labels A or B. There are also conditions such as "rest" in between, which can act as a control. Each volume consists of a great number of voxels which we refer to as dimensions or features in the MVPA process. In other kinds of studies, these features can also be single-neuron recordings or local field potentials; however, in the current project dimensions or features refer to voxels.

In our particular study subjects viewed fear and anxiety inducing stimuli, and consistent responses across subjects are measured within the following areas: temporal occipital fusiform cortex, anterior and posterior divisions of temporal fusiform cortex, right and left hippocampus, right and left amygdala, anterior and posterior divisions of parahippocampal gyrus, occipital fusiform gyrus, lingual gyrus, and intracalcarine cortex. According to this hypothesis, we applied a mask containing all the mentioned ROls (regions of interest) at the beginning of data processing. Although we would rather look through the whole brain to have a 
comprehensive study, masking is an inevitable phase due to common limitations in computational resources.

If we treat brain volumes as data points, we can place them in a multidimensional coordinate system with each dimension being a voxel's intensity. Therefore, we're transforming the 3D images into a new configuration without losing any signal. For example, we have two functional brain volumes, each consisting of a pattern of activity with only two voxels (V1 \& V2). The patterns are distinct since they are evoked by the two different stimulus categories. Here, the problem is significantly simplified so that MVPA analysis can be visualized and described easier. As depicted in Figure 3, the volumes are now transformed into red and blue data points in a $2 \mathrm{D}$ space. This response pattern space is also referred to as a representational space.

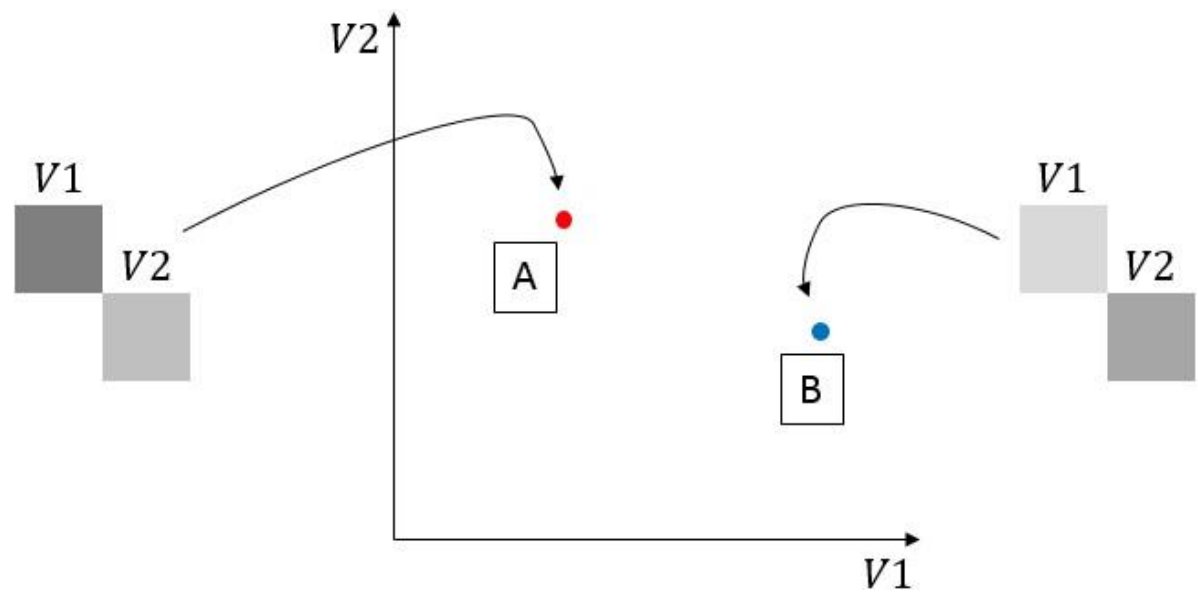

Figure 3: Transforming 3D functional volumes into a new configuration with $n$ (= number of features) dimensions. Each dimension is a voxel's intensity.

Now, if we observe independent responses to stimulus category $A / B$, the new volumes would settle in the vicinity of the red/blue data point. This is the main idea behind MVPA, and is shown in Figure 4 for more clarification. If responses to 
anxiety and fear are distinct, we would expect that data points in each category to be more correlated with each other than with the points in the opposite category.

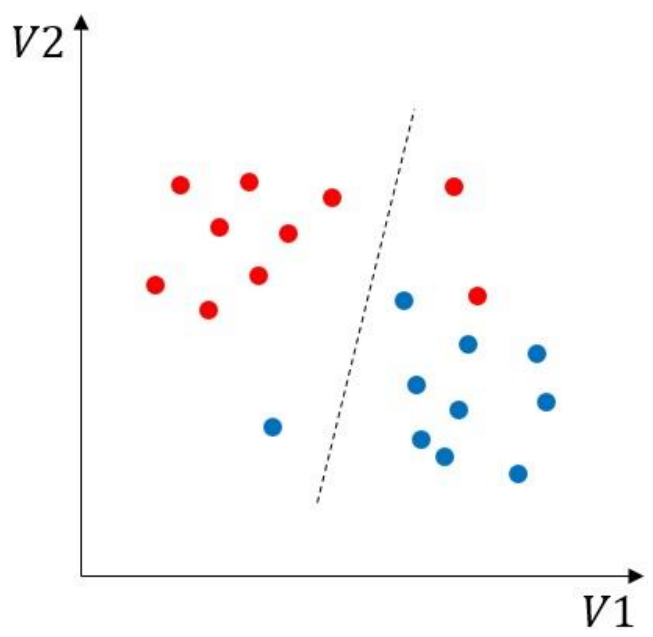

Figure 4: Independent volumes from category A/B would settle in the vicinity of the previously observed red/blue data point.

We can use the correlation described above as a similarity measure, and after learning from existing data, make predictions when new unlabeled brain volumes are observed (Norman et al., 2006; Haynes and Rees, 2006; O'Toole et al., 2007; Kriegeskorte et al., 2008). This analysis procedure is what we know in computer science as machine learning; supervised learning with labels in this particular case. In a real problem with a high-dimensional space, it is necessary to use feature selection, a form of data reduction - which renders a subspace with the most discriminative features - to avoid the curse of dimensionality. Curse of dimensionality is a phenomenon that occurs as the number of features increase, which subsequently leads to a fast growth in the volume of representational space. This results in the available data being sparse, making learning problematic. 
Therefore, with MVPA we can obtain visual voxel-wise patterns in the brain having been trained with machine learning, but also we are able to predict the category of new observed volumes without any previous knowledge of stimulus category. The dashed line in Figure 4 above is an example of a classifier model generated by a support vector machine (SVM).

In order to obtain response patterns to stimulus categories, we dissect the classifier to get the importance (or weights) of features in the dataset. This is feasible through so-called sensitivity analyzers that obtain the weights from a particular classifier; classifiers hide this information in different places. A bunch of classifiers can be used in MVPA analysis such as k-nearest neighbors (k-NN), Gaussian Naive Bayes, SVM, etc. However, not all classifiers - k-NN as an example - are accompanied with sensitivity analyzers. This has been the main reason for using support vector machines in the current study.

About four years after the idea of MVPA was introduced, the method gained momentum in 2005 with two Nature Neuroscience papers (Haynes and Rees, 2005; Kamitani and Tong, 2005). Kamitani and Tong went beyond and showed that MVPA could be used for decoding cognitive states; target of selective attention in their particular study. Haynes et al., (2007) also did the same later in their study on the intention to perform one task rather than another. Review papers also emerged that further elucidated the almost newly born multivariate approach.

One of the drawbacks of MVPA was between-subject variance of response patterns and also the difficulty of perfectly aligning individual subjects to a group representational space. All the previously illustrated steps including the model 
generation are done separately for individuals in their own space. Therefore, obtaining population response topographies would be tricky. In 2011, ten years after the first MVPA paper came out, this problem was solved with a new proposed method called hyperalignment (Haxby et al., 2011). Hyperalignment enabled transforming individual representational spaces into a common cortical model space. In our first group analysis attempt in the current study, we generated separate models in each individual space, and then transformed all the models into a common space. In this case, classification is done 20 (number of subjects) times independently with each having a total number of 340 data points for training and testing. In our second trial, however, we intended to transform all the representational spaces $(20 \times 340$ volumes $)$ into a common space without doing any individual classification. This helped us to not only have a much larger dataset and a better trained model, but also at the same time could tell us to what extent there is between-subject variance based on the classification accuracy. In other words, getting a relatively accurate result indicates low variance between subjects, and vice versa; important to increased understanding of the underlying neural processes. Due to limitations in computational resources, we were only able to merge and load subjects two by two (20 choose $2=190$ possible combinations). Although this approach would not give us as many data points as concatenating all 20 subjects' data, it enables looking through between-subject variance in pairs, as opposed to the total variability. We achieved relatively accurate common models by merging one of the subjects with each of the other individuals, resulting in 19 different combinations and therefore 19 models. Because of between-subject 
variance being greater than within-subject variance, the precision of these models were on average less than individual models' accuracies as we expected.

Although MVPA has a drawback of being computationally demanding, one of its major benefits is the ability to detect fine spatial scaled representational distinctions such as the difference between two human faces. Notice that we have used the word "drawback" and not disadvantage or problem, as advancing technologies require more resources, and the computational need will cause MVPA to be less pragmatic at the current time, but will be more pragmatic with increased computational power. Unlike MVPA, conventional univariate methods are only capable of distinguishing between categories with coarser distinctions. An example of such categories would be human faces versus objects.

Fear vs. Anxiety. The extended amygdala is a region that comprises portions of the amygdala and the bed nucleus of the stria terminalis (BST) (Alheid and Heimer, 1988). It has been shown that this region plays a decisive role in fear and anxiety conditions while encountering learned and unlearned threats (Calhoon and Tye, 2015; Fox et al., 2015; Janak and Tye, 2015; Tovote et al., 2015; Gungor and Pare, 2016; Oler et al., 2016). Furthermore, it has been demonstrated that regulation of phasic and sustained responses to these threats take place in different parts of the extended amygdala (Davis et al., 1997, 2010; Davis, 1998, 2006; Walker et al., 2003, 2009; Grillon, 2008; Walker and Davis, 2008). Examples of threats with phasic and sustained responses would be the delivery of a shock and a dark room, respectively. An earlier version of this model suggested a strict functional segregation between the central nucleus of the amygdala $(\mathrm{Ce})$ and BST, 
with Ce involved in phasic and BST in sustained responses. In the revised version, however, the Ce responds to both kinds of threat. Specifically, projections from the medial portion contributes to phasic responses while more sustained responses are mediated by projections from the lateral division of the $\mathrm{Ce}$ to the lateral division of the BST. Here, we look through responses to fear and anxiety with a multivariate pattern analysis approach. 


\section{METHODS}

\section{Participants}

A total of 20 young adults (16 females) participated in the study (mean age $=20.2$, standard deviation $=1.88)$. All participants were healthy, right handed, with normal or corrected-to-normal vision and hearing, and had no disclosed history of neurological or psychiatric disorders. Participants were recruited through oncampus flyers and an online research participation system (Sona Systems), and were paid for their participation. Written informed consent was obtained prior to experimental sessions and all experimental protocols were approved by University of Louisville's Institutional Review Board prior to data collection. No participants were excluded from any analyses.

\section{Procedure - Stimuli}

Red triangles and blue squares were used as cues to predict the presentation of a fearful face with an aversive sound or a neutral face with a neutral sound, respectively. Images of fearful and neutral faces (male and female) were acquired from the Chicago Face Database (Ma, Correl \& Wittenbrink, 2015). Audio

clips of aversive human screams ( 7 male, 7 female), along with neutral noises of conversational chatter and nature sounds (running water) were found on the internet. All audio clips were edited to 2 seconds in length and normalized for loudness. During scanning, visual stimuli were projected onto a mirror at the back 
of the scanner bore and auditory stimuli was presented binaurally through headphones.

\section{Scanning Paradigm}

Since fear can be defined as a direct or immediate threat, while anxiety tends to be more ambiguous or diffuse, the present study aimed to manipulate the "if" and "when" a threatening stimulus would occur, in order to differentiate the neural mechanisms of fear and anxiety. This was done by presenting the participants with a probability that a threatening stimulus would occur for each trial ("if"), as well as manipulating the waiting time between cue presentation and stimulus onset ("when").

For the fear condition, a " $100 \%$ " within a red triangle was displayed for 500ms. After this cue, a fearful face and human scream was immediately presented $(2000 \mathrm{~ms})$, followed by an inter-trial interval of $500 \mathrm{~ms}$ ( 4 seconds total). In the anxiety condition, probabilities inside a red triangle cue included $80 \%, 60 \%$, $40 \%$, and $20 \%$ and were presented for $500 \mathrm{~ms}$. Trials were formulated such that within the presentation of each probability, threatening stimuli did occur that percentage of the time, and across all anxiety trials, threatening stimuli occurred $50 \%$ of the time. Additionally, the anxiety condition included a variable anticipatory period before stimulus onset which ranged from $500-5000 \mathrm{~ms}$, during which time participants viewed a blank black screen. Following stimulus presentation (2 seconds), any additional time was incorporated into the inter-trial interval for a total trial length of 8 seconds. In the instances when threatening stimuli did not occur in 
the fear and anxiety conditions, a neutral face and nature noises were instead presented.

The fear and anxiety conditions were both matched with control conditions. In the neutral condition, a "100\%" was presented within a blue square, and a neutral face and conversational chatter immediately followed. The "wait" condition was cued with probabilities of $60 \%$ or $20 \%$ shown within a blue square, followed by the same variable waiting period ranging from $500-5000 \mathrm{~ms}$ before stimulus onset. For the trials in which a neutral face and conversational chatter did not occur, a neutral face and nature noises were presented.

The study was run in a hybrid mini block design, which consisted of mini blocks of 16 seconds (4 trials of fear/neutral per block, or 2 trials of anxiety/wait per block) and were presented in pseudo-random order.

After scanning, participants rated all faces using a seven-point Likert scale to assess valence $(1=$ Extremely pleasant and $7=$ Extremely Unpleasant, with 4 = Neutral). Behavioral data were analyzed using SPSS (Version 24.0.0.0; SPSS, INC.). A probability level of $p<0.05$ was considered statistically significant.

\section{Neuroimaging Methods - Imaging Data Acquisition}

Structural. All structural MRI images were acquired using a Siemens 3-T Skyra MR scanner located at the University of Louisville School of Medicine. A 20channel head coil was used for radiofrequency transmission and reception. Participants were given earplugs to reduce scanner noise, and were additionally given headphones to receive instructions and auditory stimuli. Foam padding was 
added to limit motion if additional room remained within the head coil, and a piece of folded tape was placed over the participant's forehead as a reminder to remain still throughout the scan. Structural images were obtained via a T1-weighted magnetization-prepared rapid gradient-echo sequence (MPRAGE) in 208 sagittal slices. Imaging parameters were as follows: echo time $(T E)=2.26 \mathrm{~ms}$, repetition time $(T R)=1700 \mathrm{~ms}$, flip angle $=9.0^{\circ}$, field of view $(F o V)=204 \mathrm{~mm}$, and voxel size $=0.8 \times 0.8 \times 0.8 \mathrm{~mm}$. Scan parameters were consistent for all imaging sessions associated with this study.

Functional. Functional blood oxygenation level-dependent (BOLD) images were collected using gradient-echo $\mathrm{T}^{*}$-weighted echoplanar imaging $(\mathrm{TR}=$ $3000 \mathrm{~ms} ; \mathrm{TE}=30 \mathrm{~ms} ;$ multi-band accelerator factor $=2 ; \mathrm{FoV}=192 \mathrm{~mm} ; 78$ transverse slices, $1.5 \mathrm{~mm}$ slice thickness, $1.5 \times 1.5 \times 1.5 \mathrm{~mm}$ voxels, flip angle $=$ $\left.90^{\circ}\right)$. Slices were oriented obliquely along the AC-PC line.

\section{MVPA}

There are several software packages available that facilitate the use of MVPA including the must have Python 2.x and NumPy, and additional packages such as SciPy, NiBabel, IPython, FSL, AFNI, scikit-learn, Shogun, LIBSVM, R and RPy, and matplotlib that provide more functionality. Although these packages can be installed on various operating systems, an easier way is to use NeuroDebian's virtual machine which provides many popular neuroscience packages (Hanke et al., 2010). All the mentioned packages are parts of PyMVPA, a Python-based MVPA toolbox (www.pymvpa.org) (Hanke et al., 2009). By using Python, this toolbox benefits from the many existing machine learning libraries. Around the 
same time that PyMVPA was developed, the Princeton MVPA toolbox (http://code.google.com/p/princeton-mvpa-toolbox/) was created using Matlab.

We used linear support vector machines (Linear SVM) in this study to categorize $\mathrm{fMRI}$ responses. In order to find the patterns for different conditions in the brain, we got classifiers' results about the importance of features (weights) in the dataset. In PyMVPA, support vector machines are one of the classifiers that are accompanied with so-called sensitivity analyzers. A sensitivity analyzer is an object that knows how to get the weights from a particular classifier type; each classification algorithm hides them in different places. SVM and k-nearest neighbors (kNN) were two classifiers that we utilized in this study. Not only do SVMs come with sensitivity analyzers (which is the main reason we used this classifier) but also we got more accurate classification results with it compared to kNN.

Our data for each subject was obtained in one run (named as "chunks" in MVPA analysis) consisting of 48 blocks of "rest", 13 blocks of "wait", 6 blocks of "fear", 6 blocks of "neutral", 25 blocks of "dummy", and 19 blocks of "anxiety". There were 340 samples or brain volumes in total with each block containing a different number of samples. One way to prepare the data for classification is to average all the samples within each block and do leave-one-block-out cross-validation. We did not take this approach because this way, we would only have $48+13+6+6+25$ $+19=117$ samples which were not enough for our training purposes. Instead, we took every single sample and fed them into the SVM classifier for training, i.e. leave-one-sample-out cross-validation. Our study was not initially designed for 
subsequent MVPA analysis, and that made the training process tricky. If we instead had multiple runs for each subject like the Haxby et al., (2001) study, we could easily leave runs (or chunks) out and cross-validate the models. 


\section{RESULTS}

In the first phase of our analysis, we classified fear versus neutral and anxiety versus wait for all the individuals separately in their own space. Model accuracies for fear vs. neutral ranged from $56.9 \%$ to $87.7 \%$ with a mean of $73.99 \%$ and standard deviation of $8.97 \%$. For anxiety vs. wait, they ranged from $59.1 \%$ to $80 \%$ with a mean of $68.08 \%$ and standard deviation of $4.96 \%$. Intensity normalizations were done based on neutral and wait conditions, respectively. Table 1 contains all the accuracies together with confusion matrices.

\section{Table 1}

Model accuracies and confusion matrices for fear vs. neutral (left) and anxiety vs. wait (right).

\begin{tabular}{ccccc}
\hline Subject & $\begin{array}{c}\text { Accuracy } \\
(\%)\end{array}$ & $\begin{array}{c}\text { Confusion } \\
\text { Matrix }\end{array}$ & $\begin{array}{c}\text { Accuracy } \\
(\%)\end{array}$ & $\begin{array}{c}\text { Confusion } \\
\text { Matrix }\end{array}$ \\
\hline $\mathbf{1}$ & 75.4 & {$\left[\begin{array}{cc}26 & 10 \\
6 & 23\end{array}\right]$} & 67.0 & {$\left[\begin{array}{ll}34 & 16 \\
22 & 43\end{array}\right]$} \\
\hline $\mathbf{2}$ & 83.1 & {$\left[\begin{array}{cc}27 & 6 \\
5 & 27\end{array}\right]$} & 67.8 & {$\left[\begin{array}{ll}36 & 17 \\
20 & 42\end{array}\right]$} \\
\hline $\mathbf{3}$ & 86.2 & {$\left[\begin{array}{cc}27 & 4 \\
5 & 29\end{array}\right]$} & 65.2 & {$\left[\begin{array}{ll}33 & 17 \\
23 & 42\end{array}\right]$} \\
\hline $\mathbf{4}$ & 83.1 & {$\left[\begin{array}{cc}26 & 5 \\
6 & 28\end{array}\right]$} & 70.4 & {$\left[\begin{array}{ll}33 & 11 \\
23 & 48\end{array}\right]$} \\
\hline
\end{tabular}




\begin{tabular}{|c|c|c|c|c|c|c|}
\hline 5 & 81.5 & {$\left[\begin{array}{c}26 \\
6\end{array}\right.$} & $\left.\begin{array}{c}6 \\
27\end{array}\right]$ & 63.5 & {$\left[\begin{array}{l}31 \\
25\end{array}\right.$} & $\left.\begin{array}{l}17 \\
42\end{array}\right]$ \\
\hline 6 & 67.7 & {$\left[\begin{array}{l}21 \\
11\end{array}\right.$} & $\left.\begin{array}{l}10 \\
23\end{array}\right]$ & 70.4 & {$\left[\begin{array}{l}38 \\
18\end{array}\right.$} & $\left.\begin{array}{l}16 \\
43\end{array}\right]$ \\
\hline 7 & 61.5 & {$\left[\begin{array}{l}18 \\
14\end{array}\right.$} & $\left.\begin{array}{l}11 \\
22\end{array}\right]$ & 69.6 & {$\left[\begin{array}{l}37 \\
19\end{array}\right.$} & $\left.\begin{array}{l}16 \\
43\end{array}\right]$ \\
\hline 8 & 73.8 & {$\left[\begin{array}{c}24 \\
8\end{array}\right.$} & $\left.\begin{array}{c}9 \\
24\end{array}\right]$ & 61.7 & {$\left[\begin{array}{l}32 \\
24\end{array}\right.$} & $\left.\begin{array}{l}20 \\
39\end{array}\right]$ \\
\hline 9 & 72.3 & {$\left[\begin{array}{c}23 \\
9\end{array}\right.$} & $\left.\begin{array}{c}9 \\
24\end{array}\right]$ & 70.4 & {$\left[\begin{array}{l}36 \\
20\end{array}\right.$} & $\left.\begin{array}{l}14 \\
45\end{array}\right]$ \\
\hline 10 & 73.8 & {$\left[\begin{array}{l}20 \\
12\end{array}\right.$} & $\left.\begin{array}{c}5 \\
28\end{array}\right]$ & 59.1 & {$\left[\begin{array}{l}30 \\
26\end{array}\right.$} & $\left.\begin{array}{l}21 \\
38\end{array}\right]$ \\
\hline 11 & 60.0 & {$\left[\begin{array}{l}16 \\
16\end{array}\right.$} & $\left.\begin{array}{l}10 \\
23\end{array}\right]$ & 80.0 & {$\left[\begin{array}{l}43 \\
13\end{array}\right.$} & $\left.\begin{array}{l}10 \\
49\end{array}\right]$ \\
\hline 12 & 69.2 & {$\left[\begin{array}{l}21 \\
11\end{array}\right.$} & $\left.\begin{array}{c}9 \\
24\end{array}\right]$ & 69.6 & {$\left[\begin{array}{l}37 \\
19\end{array}\right.$} & $\left.\begin{array}{l}16 \\
43\end{array}\right]$ \\
\hline 13 & 86.2 & {$\left[\begin{array}{c}25 \\
7\end{array}\right.$} & $\left.\begin{array}{c}2 \\
31\end{array}\right]$ & 71.3 & {$\left[\begin{array}{l}35 \\
21\end{array}\right.$} & $\left.\begin{array}{l}12 \\
47\end{array}\right]$ \\
\hline 14 & 87.7 & {$\left[\begin{array}{c}27 \\
5\end{array}\right.$} & $\left.\begin{array}{c}3 \\
30\end{array}\right]$ & 62.6 & {$\left[\begin{array}{l}30 \\
26\end{array}\right.$} & $\left.\begin{array}{l}17 \\
42\end{array}\right]$ \\
\hline 15 & 61.5 & {$\left[\begin{array}{l}19 \\
13\end{array}\right.$} & $\left.\begin{array}{l}12 \\
21\end{array}\right]$ & 69.6 & {$\left[\begin{array}{l}38 \\
18\end{array}\right.$} & $\left.\begin{array}{l}17 \\
42\end{array}\right]$ \\
\hline 16 & 72.3 & {$\left[\begin{array}{l}21 \\
11\end{array}\right.$} & $\left.\begin{array}{c}7 \\
26\end{array}\right]$ & 64.3 & {$\left[\begin{array}{l}36 \\
20\end{array}\right.$} & $\left.\begin{array}{l}21 \\
38\end{array}\right]$ \\
\hline 17 & 56.9 & {$\left[\begin{array}{l}18 \\
14\end{array}\right.$} & $\left.\begin{array}{l}14 \\
19\end{array}\right]$ & 60.9 & {$\left[\begin{array}{l}32 \\
24\end{array}\right.$} & $\left.\begin{array}{l}21 \\
38\end{array}\right]$ \\
\hline 18 & 78.5 & {$\left[\begin{array}{c}24 \\
8\end{array}\right.$} & $\left.\begin{array}{c}6 \\
27\end{array}\right]$ & 73.9 & {$\left[\begin{array}{l}37 \\
19\end{array}\right.$} & $\left.\begin{array}{l}11 \\
48\end{array}\right]$ \\
\hline
\end{tabular}




\begin{tabular}{ccccc}
\hline 19 & 76.9 & {$\left[\begin{array}{cc}23 & 6 \\
9 & 27\end{array}\right]$} & 71.3 & {$\left[\begin{array}{ll}37 & 14 \\
19 & 45\end{array}\right]$} \\
\hline $\mathbf{2 0}$ & 72.3 & {$\left[\begin{array}{cc}20 & 6 \\
12 & 27\end{array}\right]$} & 73.0 & {$\left[\begin{array}{ll}40 & 15 \\
16 & 44\end{array}\right]$} \\
\hline
\end{tabular}

The following chart displays model accuracies for fear and anxiety in adjacent red and blue bars for better comparison. It is apparent that fear is more easily differentiated from neutral than anxiety is from wait.

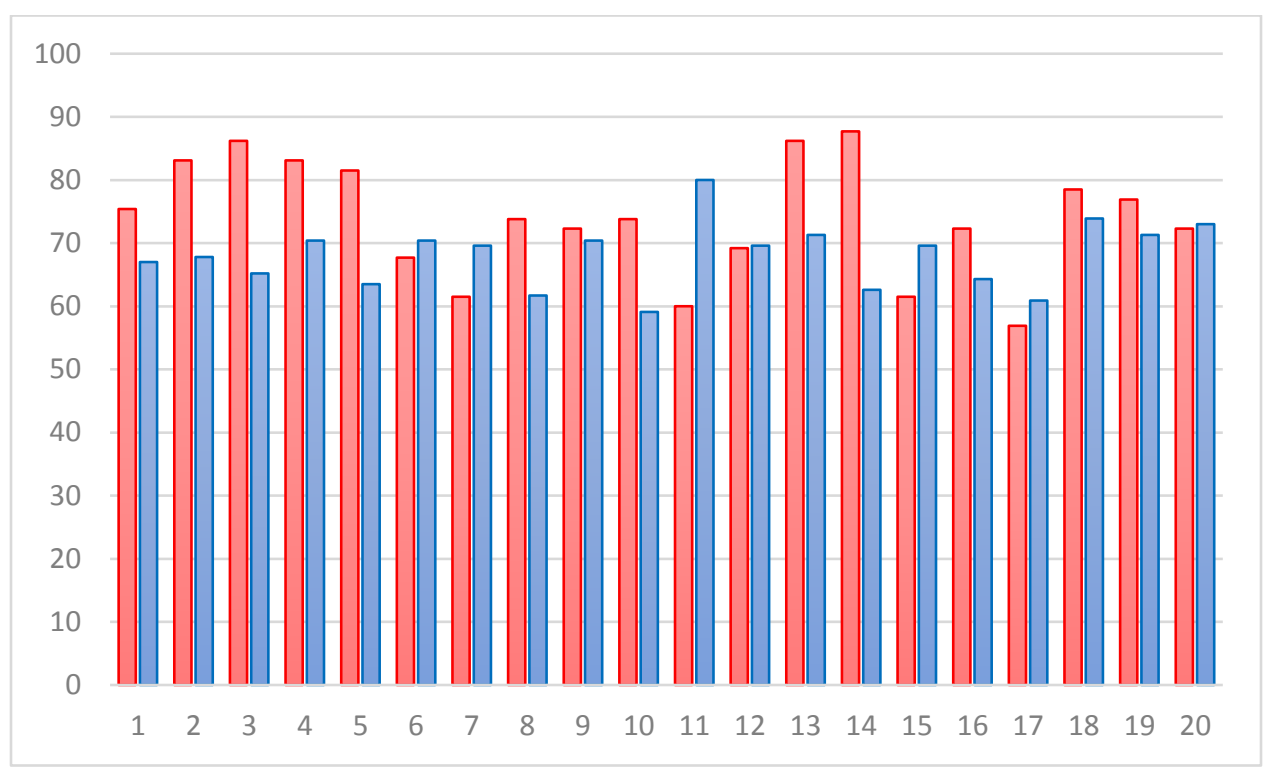

Figure 5: Fear vs. neutral (red) and anxiety vs. wait (blue) classification results for all the 20 subjects.

We classified fear versus anxiety afterwards, once with normalizing based on neutral, and the second time based on wait since all volumes have to be normalized based on the same condition in each classification trial. The two sets of results were very close with minimums of $55.7 \%$ and $56.8 \%$, maximums of 
$86.4 \%$ and $86.4 \%$, means of $72.06 \%$ and $72.50 \%$, and standard deviations of $7.74 \%$ and $7.48 \%$. All the model accuracies with confusion matrices are listed in Table 2.

\section{Table 2}

Model accuracies and confusion matrices for fear vs. anxiety with normalization based on neutral (left) and based on wait (right).

\begin{tabular}{|c|c|c|c|c|}
\hline Subject & $\begin{array}{c}\text { Accuracy } \\
(\%)\end{array}$ & $\begin{array}{c}\text { Confusion } \\
\text { Matrix }\end{array}$ & $\begin{array}{c}\text { Accuracy } \\
(\%)\end{array}$ & $\begin{array}{c}\text { Confusion } \\
\text { Matrix }\end{array}$ \\
\hline 1 & 68.2 & {$\left[\begin{array}{cc}50 & 22 \\
6 & 10\end{array}\right]$} & 69.3 & {$\left[\begin{array}{cc}51 & 22 \\
5 & 10\end{array}\right]$} \\
\hline 2 & 77.3 & {$\left[\begin{array}{cc}51 & 15 \\
5 & 17\end{array}\right]$} & 72.7 & {$\left[\begin{array}{cc}49 & 17 \\
7 & 15\end{array}\right]$} \\
\hline 3 & 73.9 & {$\left[\begin{array}{cc}54 & 21 \\
2 & 11\end{array}\right]$} & 75.0 & {$\left[\begin{array}{cc}53 & 19 \\
3 & 13\end{array}\right]$} \\
\hline 4 & 83.0 & {$\left[\begin{array}{cc}48 & 7 \\
8 & 25\end{array}\right]$} & 84.1 & {$\left[\begin{array}{cc}50 & 8 \\
6 & 24\end{array}\right]$} \\
\hline 5 & 73.9 & {$\left[\begin{array}{cc}49 & 16 \\
7 & 16\end{array}\right]$} & 75.0 & {$\left[\begin{array}{cc}50 & 16 \\
6 & 16\end{array}\right]$} \\
\hline 6 & 78.4 & {$\left[\begin{array}{cc}52 & 15 \\
4 & 17\end{array}\right]$} & 75.0 & {$\left[\begin{array}{cc}50 & 16 \\
6 & 16\end{array}\right]$} \\
\hline 7 & 67.0 & {$\left[\begin{array}{cc}50 & 23 \\
6 & 9\end{array}\right]$} & 70.5 & {$\left[\begin{array}{cc}50 & 20 \\
6 & 12\end{array}\right]$} \\
\hline 8 & 71.6 & {$\left[\begin{array}{cc}48 & 17 \\
8 & 15\end{array}\right]$} & 70.5 & {$\left[\begin{array}{cc}48 & 18 \\
8 & 14\end{array}\right]$} \\
\hline 9 & 75.0 & {$\left[\begin{array}{cc}52 & 18 \\
4 & 14\end{array}\right]$} & 75.0 & {$\left[\begin{array}{cc}52 & 18 \\
4 & 14\end{array}\right]$} \\
\hline 10 & 69.3 & {$\left[\begin{array}{cc}50 & 21 \\
6 & 11\end{array}\right]$} & 71.6 & {$\left[\begin{array}{cc}51 & 20 \\
5 & 12\end{array}\right]$} \\
\hline
\end{tabular}




\begin{tabular}{ccccc}
\hline 11 & 73.9 & {$\left[\begin{array}{cc}53 & 20 \\
3 & 12\end{array}\right]$} & 75.0 & {$\left[\begin{array}{cc}54 & 20 \\
2 & 12\end{array}\right]$} \\
\hline 12 & 85.2 & {$\left[\begin{array}{cc}52 & 9 \\
4 & 23\end{array}\right]$} & 85.2 & {$\left[\begin{array}{cc}52 & 9 \\
4 & 23\end{array}\right]$} \\
\hline $\mathbf{1 3}$ & 73.9 & {$\left[\begin{array}{cc}48 & 15 \\
8 & 17\end{array}\right]$} & 75.0 & {$\left[\begin{array}{cc}49 & 15 \\
7 & 17\end{array}\right]$} \\
\hline $\mathbf{1 4}$ & 86.4 & {$\left[\begin{array}{cc}55 & 11 \\
1 & 21\end{array}\right]$} & 86.4 & {$\left[\begin{array}{cc}55 & 11 \\
1 & 21\end{array}\right]$} \\
\hline $\mathbf{1 5}$ & 58.0 & {$\left[\begin{array}{cc}42 & 23 \\
14 & 9\end{array}\right]$} & 60.2 & {$\left[\begin{array}{cc}44 & 23 \\
12 & 9\end{array}\right]$} \\
\hline $\mathbf{1 6}$ & 55.7 & {$\left[\begin{array}{cc}40 & 23 \\
16 & 9\end{array}\right]$} & 56.8 & {$\left[\begin{array}{cc}42 & 24 \\
14 & 8\end{array}\right]$} \\
\hline $\mathbf{1 7}$ & 67.0 & {$\left[\begin{array}{cc}51 & 24 \\
5 & 8\end{array}\right]$} & 65.9 & {$\left[\begin{array}{cc}52 & 26 \\
4 & 6\end{array}\right]$} \\
\hline $\mathbf{1 0}$ & 70.5 & {$\left[\begin{array}{cc}49 & 19 \\
7 & 13\end{array}\right]$} & 75.0 & {$\left[\begin{array}{cc}50 & 16 \\
6 & 16\end{array}\right]$} \\
\hline $\mathbf{2 0}$ & 68.2 & {$\left[\begin{array}{cc}44 & 16 \\
12 & 16\end{array}\right]$} & 70.5 & {$\left[\begin{array}{cc}45 & 15 \\
11 & 17\end{array}\right]$} \\
\hline
\end{tabular}

Figure 6 visualizes the closeness of the two model accuracies for each subject. As mentioned above, the only difference between these pairs of models is the conditions on which data is normalized. 


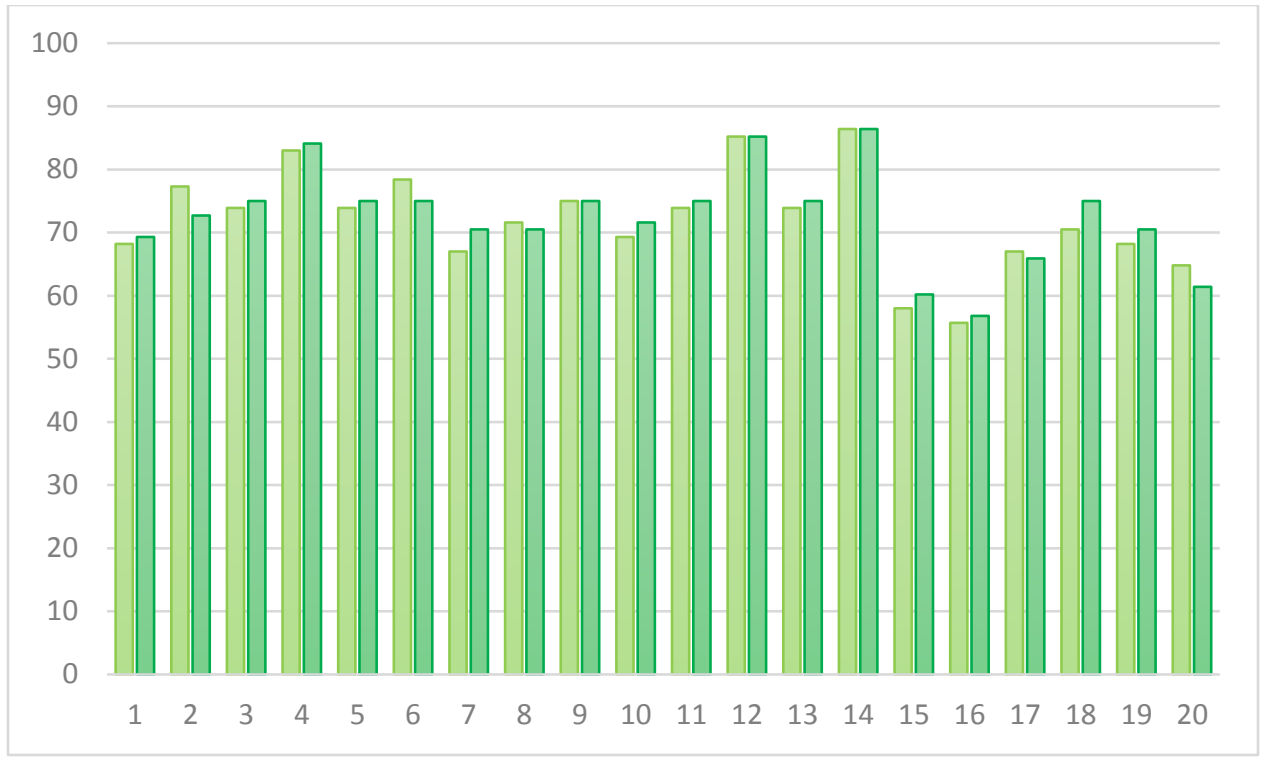

Figure 6: Fear vs. anxiety normalized based on neutral (lime) and based on wait (dark green) classification results for all the 20 subjects.

In the group analysis phase, we transformed all individual models for fear vs. neutral, anxiety vs. wait, and fear vs. anxiety normalized based on wait to a standard space with $1 \mathrm{~mm}^{3}$ resolution. Although fear vs. anxiety models with normalization based on both neutral and wait conditions were at hand, we used the latter due to slightly higher accuracies. In order to visualize the response patterns associated with these models, they were then projected back to 3D brain volumes, binarized, and added together, enabling us to see all the voxels that were activated at least once by one of the individuals. So if a voxel is on in the final result, it could be because of more than one (up to 20) subject sharing that voxel in their response patterns. We limited this accumulated pattern by accepting voxels that were activated in at least 8 (Figure 7 ) or at least 10 (Figure 8 ) of the individual patterns. Red/blue/green patterns represent voxels that are most discriminative for distinguishing between fear vs. neutral/anxiety vs. wait/fear vs. anxiety conditions. 


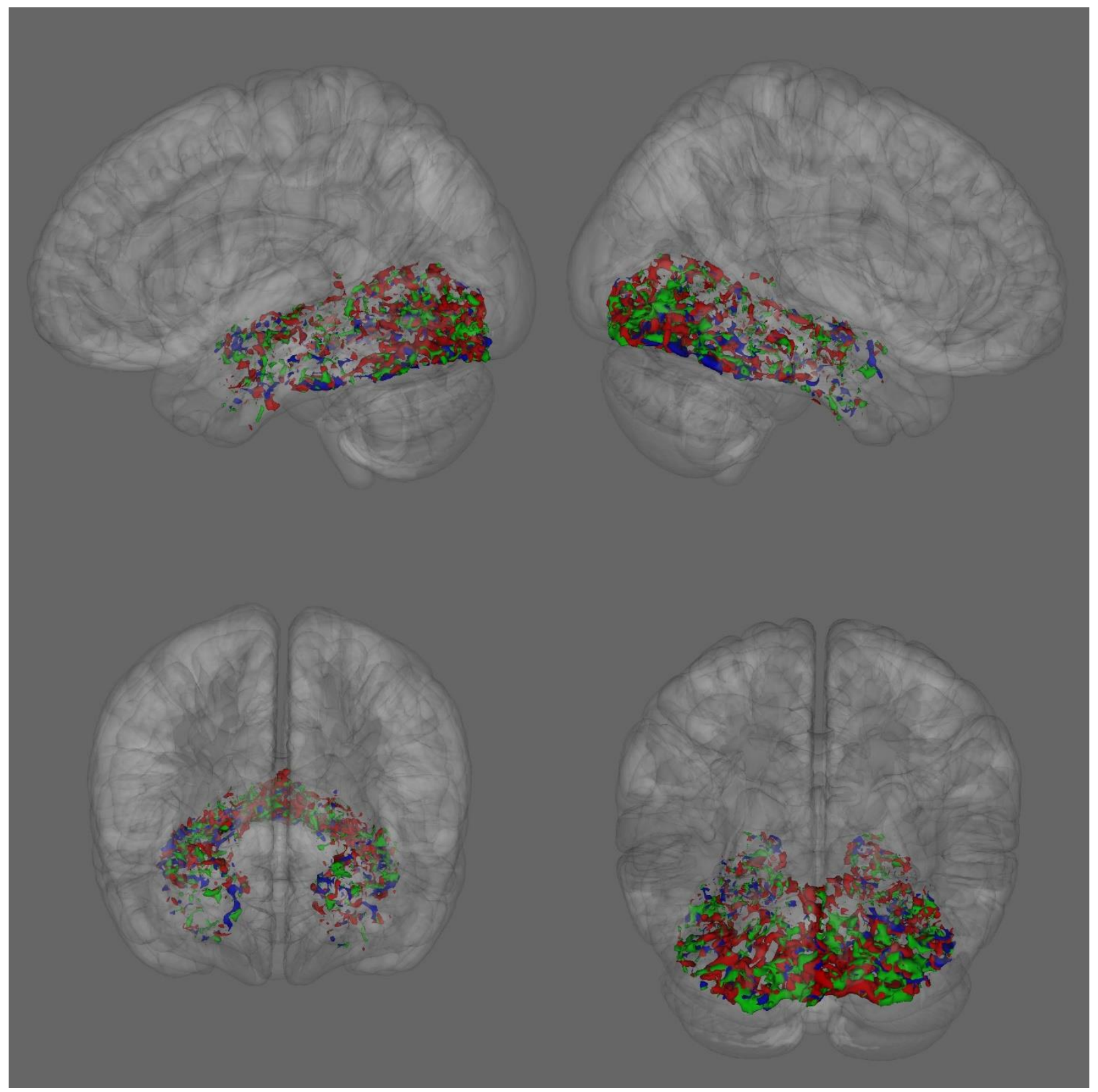

Figure 7: 3D views of fear vs. neutral (red), anxiety vs. wait (blue), and fear vs. anxiety (green) patterns, shared by at least 8 of the individuals. 


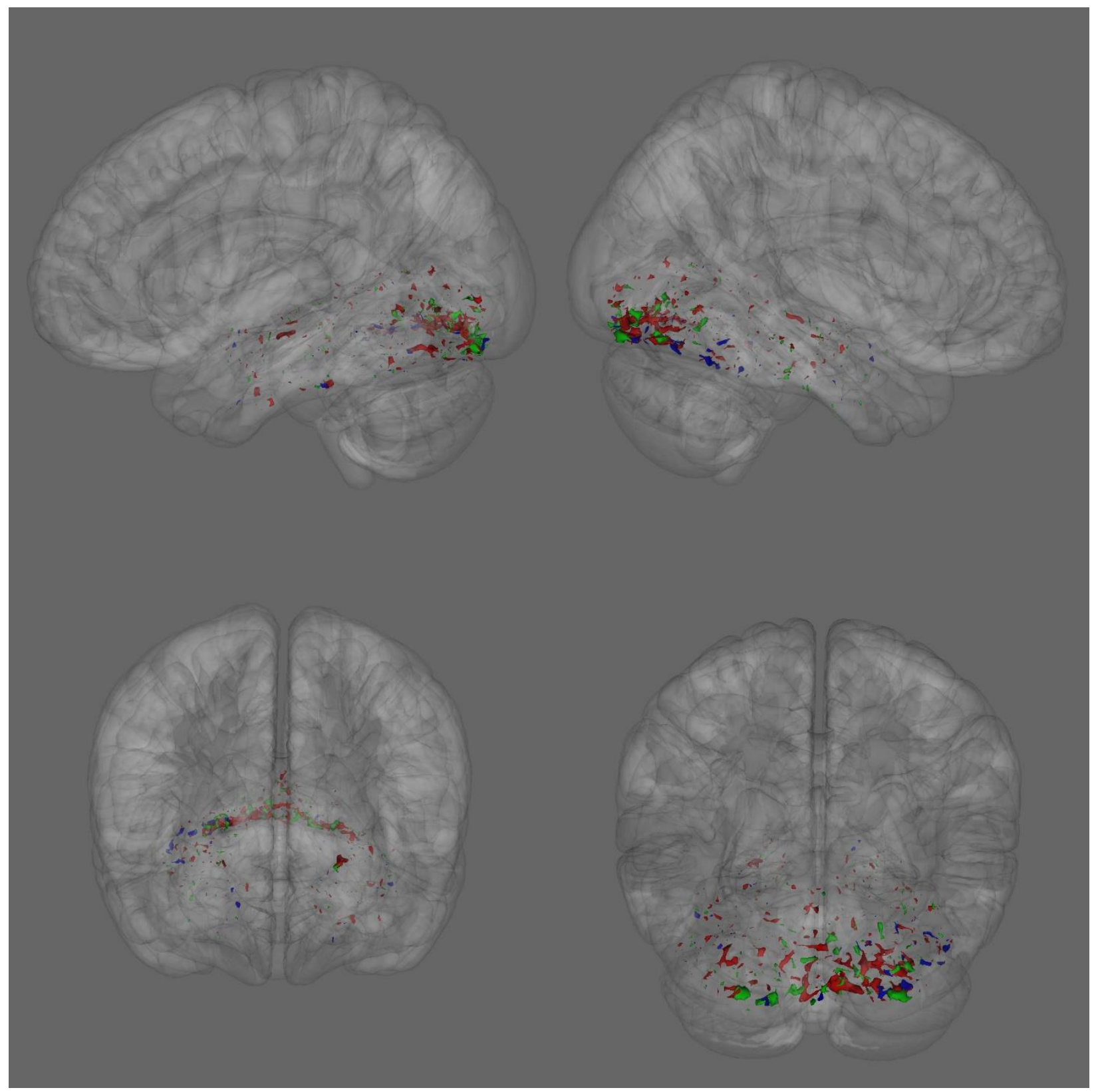

Figure 8: 3D views of fear vs. neutral (red), anxiety vs. wait (blue), and fear vs. anxiety (green) patterns, shared by at least 10 of the individuals. 
Further, we captured ventral views of the patterns to look through portions of them inside the amygdala, hippocampus, and ventral visual processing stream.

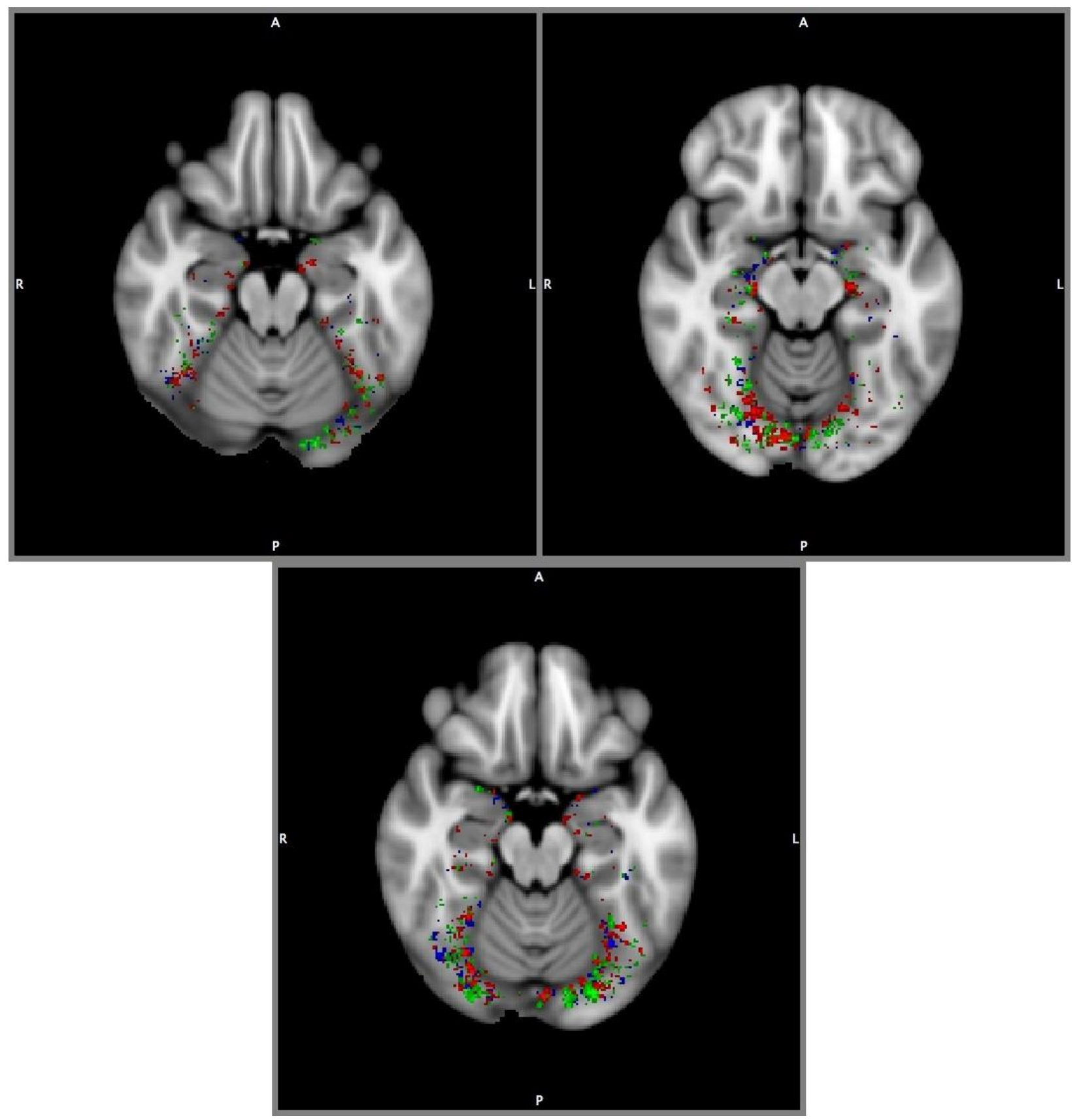

Figure 9: Ventral views of portions of the patterns from the amygdala (top left), hippocampus (top right), and ventral visual processing stream (bottom). 
Our final attempt was to merge functional data of individuals and do classification on a larger number of data points which are originally brain volumes. Because of memory limitations as mentioned before, we merged subjects into pairs and could not go further. In particular, after transforming all the individual data into a $2 \mathrm{~mm}^{3}$ standard space, we merged the first subject with each of the other 19. A $2 \mathrm{~mm}^{3}$ space was used because we ended up having data larger than memory capacity of the NeuroDebian machine. Table 3 contains fear vs. neutral model accuracies and confusion matrices for all the 19 combinations. Here we used leave-two-samples-out (sample 1 of the first subject \& sample 1 of the second subject) cross-validation which results in 340 iterations.

\section{Table 3}

Model accuracies and confusion matrices for fear vs. neutral for 19 pairs of subjects, all compared to the first subject.

\begin{tabular}{|c|c|c|c|c|c|}
\hline Subjects & $\begin{array}{c}\text { Accuracy } \\
\text { (\%) }\end{array}$ & $\begin{array}{c}\text { Confusion } \\
\text { Matrix }\end{array}$ & Subjects & $\begin{array}{c}\text { Accuracy } \\
\text { (\%) }\end{array}$ & $\begin{array}{c}\text { Confusion } \\
\text { Matrix }\end{array}$ \\
\hline $1 \& 1$ & -- & -- & $1 \& 11$ & 68.5 & {$\left[\begin{array}{ll}41 & 18 \\
23 & 48\end{array}\right]$} \\
\hline $1 \& 2$ & 69.2 & {$\left[\begin{array}{ll}45 & 21 \\
19 & 45\end{array}\right]$} & $1 \& 12$ & 65.4 & {$\left[\begin{array}{ll}41 & 22 \\
23 & 44\end{array}\right]$} \\
\hline $1 \& 3$ & 70.0 & {$\left[\begin{array}{ll}43 & 18 \\
21 & 48\end{array}\right]$} & $1 \& 13$ & 66.9 & {$\left[\begin{array}{ll}42 & 21 \\
22 & 45\end{array}\right]$} \\
\hline $1 \& 4$ & 65.4 & {$\left[\begin{array}{ll}40 & 21 \\
24 & 45\end{array}\right]$} & $1 \& 14$ & 72.3 & {$\left[\begin{array}{ll}45 & 17 \\
19 & 49\end{array}\right]$} \\
\hline $1 \& 5$ & 66.9 & {$\left[\begin{array}{ll}41 & 20 \\
23 & 46\end{array}\right]$} & $1 \& 15$ & 63.8 & {$\left[\begin{array}{ll}39 & 22 \\
25 & 44\end{array}\right]$} \\
\hline
\end{tabular}




\begin{tabular}{|c|c|c|c|c|c|c|c|}
\hline $1 \& 6$ & 63.1 & {$\left[\begin{array}{l}40 \\
24\end{array}\right.$} & $\left.\begin{array}{l}24 \\
42\end{array}\right]$ & $1 \& 16$ & 66.9 & {$\left[\begin{array}{l}41 \\
23\end{array}\right.$} & $\left.\begin{array}{l}20 \\
46\end{array}\right]$ \\
\hline $1 \& 7$ & 70.8 & {$\left[\begin{array}{l}43 \\
21\end{array}\right.$} & $\left.\begin{array}{l}17 \\
49\end{array}\right]$ & $1 \& 17$ & 66.9 & {$\left[\begin{array}{l}43 \\
21\end{array}\right.$} & $\left.\begin{array}{l}22 \\
44\end{array}\right]$ \\
\hline $1 \& 8$ & 70.0 & {$\left[\begin{array}{l}44 \\
20\end{array}\right.$} & $\left.\begin{array}{l}19 \\
47\end{array}\right]$ & $1 \& 18$ & 70.8 & {$\left[\begin{array}{l}46 \\
18\end{array}\right.$} & $\left.\begin{array}{l}20 \\
46\end{array}\right]$ \\
\hline $1 \& 9$ & 63.1 & {$\left[\begin{array}{l}36 \\
28\end{array}\right.$} & $\left.\begin{array}{l}20 \\
46\end{array}\right]$ & $1 \& 19$ & 63.1 & {$\left[\begin{array}{l}40 \\
24\end{array}\right.$} & $\left.\begin{array}{l}24 \\
42\end{array}\right]$ \\
\hline $1 \& 10$ & 61.5 & {$\left[\begin{array}{l}38 \\
26\end{array}\right.$} & $\left.\begin{array}{l}24 \\
42\end{array}\right]$ & $1 \& 20$ & 60.8 & {$\left[\begin{array}{l}38 \\
26\end{array}\right.$} & $\left.\begin{array}{l}25 \\
41\end{array}\right]$ \\
\hline
\end{tabular}

In a similar way, we can classify other possible combinations and compare between-subject variabilities with one another and also with within-subject variance of each individual. 


\section{DISCUSSION}

The main goal of this study was to determine whether fear and anxiety emotions have distinct neural correlates, using a MVPA approach. We successfully found different patterns for the two conditions through classification attempts on individuals and combining their results. Moreover, we tried merging subjects and then classifying conditions to see if we could get more accurate models and also to examine the variance between subjects.

As results showed, models that classified fear \& neutral conditions were more accurate compared to anxiety \& wait. This indicates that fear is relatively more distant from its control condition - and therefore better distinguishable - than anxiety from wait. Next, we classified fear versus anxiety to see how different their response patterns are. Models with $72 \%$ average accuracy were achieved, through which the most discriminatory features between fear and anxiety were found. We combined all the individual fear vs. neutral models as well as anxiety vs. wait and fear vs. anxiety to reach general grouped models. These models were eventually visualized in red, blue, and green colors respectively.

The amygdala and hippocampus areas contained more of voxels in red which indicates their importance for differentiating fear. Moreover, we observed a significant number of red voxels in the whole inferotemporal (IT) cortex, showing that subjects share a more common fear response. None of the colors were 
dominant in the ventral visual processing stream. This type of analysis would not be possible with conventional univariate methods.

In our last step, we measured the variance between the first subject and each of the other subjects by classifying data containing combinations of them. As explained before, a well-differentiating classifier would show lower betweensubject variance. Although classification accuracies were fairly above chance, they couldn't reach the precision of individual models because of within-subject variance being lower than between-subject variance.

Finally, we propose a way on how to consider the different models of neural responses which vary in the level of precision; the multivariate and univariate models in particular. As discussed, MVPA provides us with more informative models with which we have deeper views into patterns of voxels. However, the brain can still be viewed as a set of regions, and be examined through univariate models. Hence, these models should not just get discarded after the advent of MVPA. So even though the two kinds of analysis offer different scales, they are both true representations of the same thing and should coexist; no single model can explain the data completely. Therefore, we suggest maintaining all the model types, but with different probabilities attached to each type. These probabilities actually indicate how well each model type explains the data, resulting in a stable general model. Bayesian program learning (BPL) which was introduced by Lake, B. M. et al., (2015) also suggests the same idea. 


\section{REFERENCES}

1- Haxby, J.V., Gobbini, M.I., Furey, M.L., Ishai, A., Schouten, J.L., Pietrini, P., 2001. Distributed and overlapping representations of faces and objects in ventral temporal cortex. Science 293, 2425-2430.

2- Vanhaudenhuyse, A. et al. (2010) Default network connectivity reflects the level of consciousness in non-communicative brain-damaged patients. Brain: J. Neurol. 133, 161-171.

3- Kanjlia, S., Lane, C., Feigenson, L., \& Bedny, M. (2016). Absence of visual experience modifies the neural basis of numerical thinking. Proceedings of the National Academy of Sciences, 201524982.

4- Jung-Beeman, M. (2005). Bilateral brain processes for comprehending natural language. Trends Cogn. Sci. 9, 512-518.

5- Baars, B.J., \& Gage, N.M. (Eds.). (2010). Cognition, brain, and consciousness: Introduction to cognitive neuroscience. London: Elsevier.

6- Singh, K.D., 2012. Which "neural activity" do you mean? fMRI, MEG, oscillations and neurotransmitters. Neurolmage Twenty years of fMRI: the science and the stories 62, 1121-1130.

7- Norman, K.A., Polyn, S.M., Detre, G.J., and Haxby, J.V. (2006). Beyond mindreading: multi-voxel pattern analysis of fMRI data. Trends Cogn. Sci. (Regul. Ed.) 10, 424-430. 
8- Haynes, J.-D., and Rees, G. (2006). Decoding mental states from brain activity in humans. Nat. Rev. Neurosci. 7, 523-534.

9- O'Toole, A.J., Jiang, F., Abdi, H., Pe' nard, N., Dunlop, J.P., and Parent, M.A. (2007). Theoretical, statistical, and practical perspectives on pattern-based classification approaches to the analysis of functional neuroimaging data. J. Cogn. Neurosci. 19, 1735-1752.

10-Kriegeskorte, N., Mur, M., and Bandettini, P. (2008). Representational similarity analysis - connecting the branches of systems neuroscience. Front Syst Neurosci 2, 4.

11-Haynes, J.D., Rees, G., 2005. Predicting the orientation of invisible stimuli from activity in primary visual cortex. Nat. Neurosci. 8, 686-691.

12-Kamitani, Y., Tong, F., 2005. Decoding the visual and subjective contents of the human brain. Nat. Neurosci. 8, 679-685.

13-Haynes, J.D., Sakai, K., Rees, G., Gilbert, S., Frith, C., Passingham, R.E., 2007. Reading hidden intentions in the human brain. Curr. Biol. 17, 323-328.

14-Haxby, J.V., Guntupalli, J.S., Connolly, A.C., Halchenko, Y.O., Conroy, B.R., Gobbini, M.I., Hanke, M., Ramadge, P.J., 2011. A common, high-dimensional model of the representational space in human ventral temporal cortex. Neuron $72,404-416$.

15-Alheid GF, Heimer L (1988) New perspectives in basal forebrain organization of special relevance for neuropsychiatric disorders: the striatopallidal, amygdaloid, and corticopetal components of substantia innominata. Neuroscience 27:1-39. 
16-Calhoon GG, Tye KM (2015) Resolving the neural circuits of anxiety. Nat Neurosci 18:1394-1404.

17-Fox AS, Oler JA, Tromp do PM, Fudge JL, Kalin NH (2015) Extending the amygdala in theories of threat processing. Trends Neurosci 38:319 -329.

18-Janak PH, Tye KM (2015) From circuits to behaviour in the amygdala. Nature $517: 284-292$.

19-Tovote P, Fadok JP, Lu"thi A (2015) Neuronal circuits for fear and anxiety. Nat Rev Neurosci 16:317-331.

20-Gungor NZ, Pare' D (2016) Functional heterogeneity in the bed nucleus of the stria terminalis. J Neurosci 36:8038-8049.

21-Oler JA, Fox AS, Shackman AJ, KalinNH (2016) The central nucleus of the amygdala is a critical substrate for individual differences in anxiety. In: Living without an amygdala (Amaral DG, Adolphs R, eds). New York: Guilford.

22-Davis M, Walker DL, Lee Y (1997) Roles of the amygdala and bed nucleus of the stria terminalis in fear and anxiety measured with the acoustic startle reflex: possible relevance to PTSD. Ann N Y Acad Sci 821:305-331.

23-Davis M, Walker DL, Miles L, Grillon C (2010) Phasic vs sustained fear in rats and humans: role of the extended amygdala in fear vs anxiety. Neuropsychopharmacology 35:105-135.

24-Davis M (1998) Are different parts of the extended amygdala involved in fear versus anxiety? Biol Psychiatry 44:1239 -1247.

25-Davis M (2006) Neural systems involved in fear and anxiety measured with fear-potentiated startle. Am Psychol 61:741-756. 
26-Walker DL, Toufexis DJ, DavisM (2003) Role of the bed nucleus of the stria terminalis versus the amygdala in fear, stress, and anxiety. Eur J Pharmacol 563:199-216.

27-Walker DL, Miles LA, Davis M (2009) Selective participation of the bed nucleus of the stria terminalis and CRF in sustained anxiety-like versus phasic fear-like responses. Prog Neuropsychopharmacol Biol Psychiatry 33:1291-1308.

28-Grillon C (2008) Models and mechanisms of anxiety: evidence from startle studies. Psychopharmacology (Berl) 199:421- 437.

29-Walker DL, Davis M (2008) Role of the extended amygdala in shortduration versus sustained fear: a tribute to Dr. Lennart Heimer. Brain Struct Funct 213:29-42.

30-Ma, Correll, \& Wittenbrink (2015). The Chicago Face Database: A Free Stimulus Set of Faces and Norming Data. Behavior Research Methods, 47, 1122-1135.

31-Hanke, M., Halchenko, Y. O., Haxby, J. V. \& Pollmann, S. (2010). Improving efficiency in cognitive neuroscience research with NeuroDebian. Poster presented at the annual meeting of the Cognitive Neuroscience Society, Montréal, Canada.

32-Hanke, M., Halchenko, Y.O., Sederberg, P.B., Hanson, S.J., Haxby, J.V., Pollman, S., 2009. PyMVPA: a Python toolbox for multivariate pattern analysis of fMRI data. Neuroinformatics 7, 37-53. 
33-Lake, B. M., Salakhutdinov, R., \& Tenenbaum, J. B. (2015). Human-level concept learning through probabilistic program induction. Science, 350 (6266), $1332-1338$. 


\section{APPENDIX}

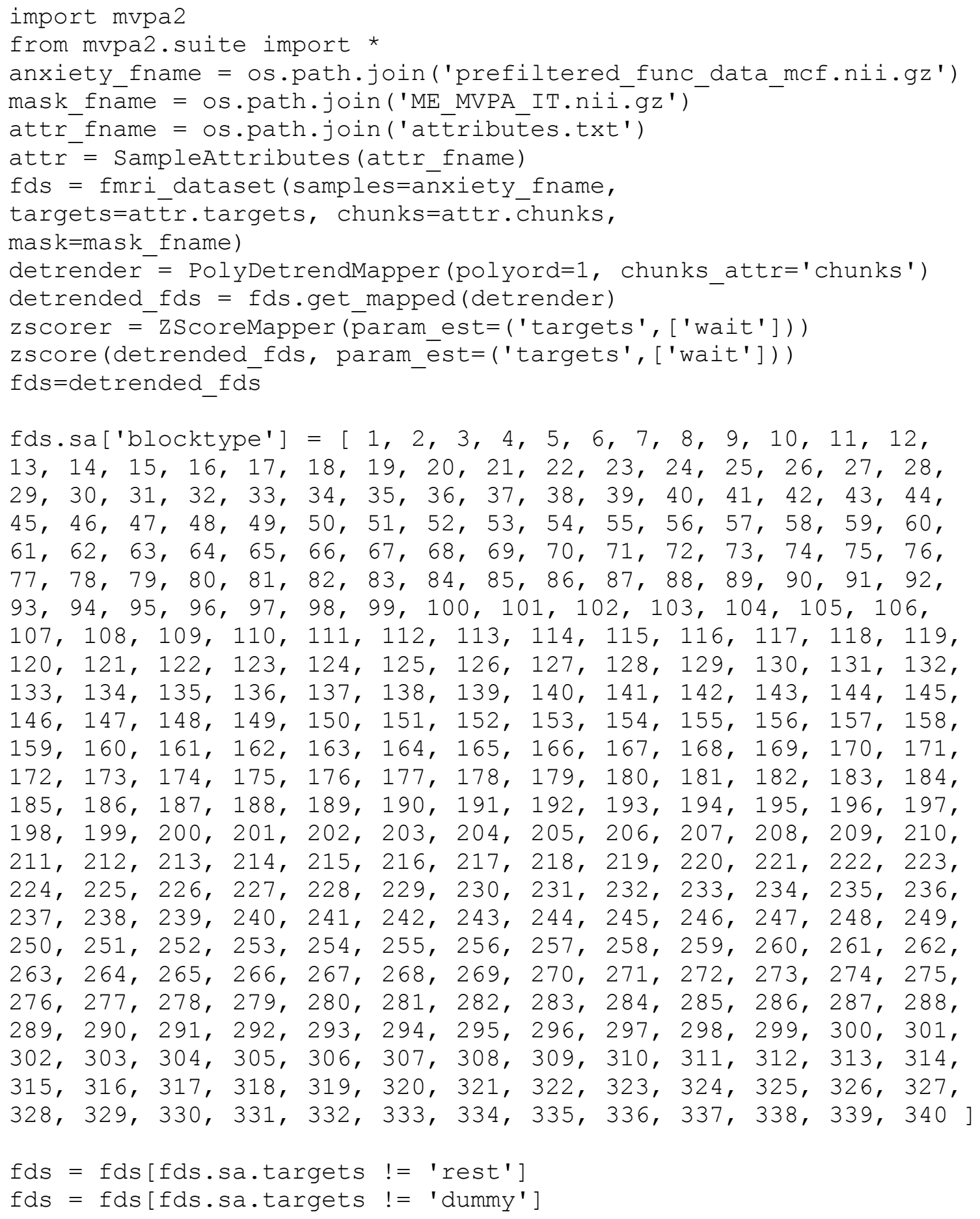




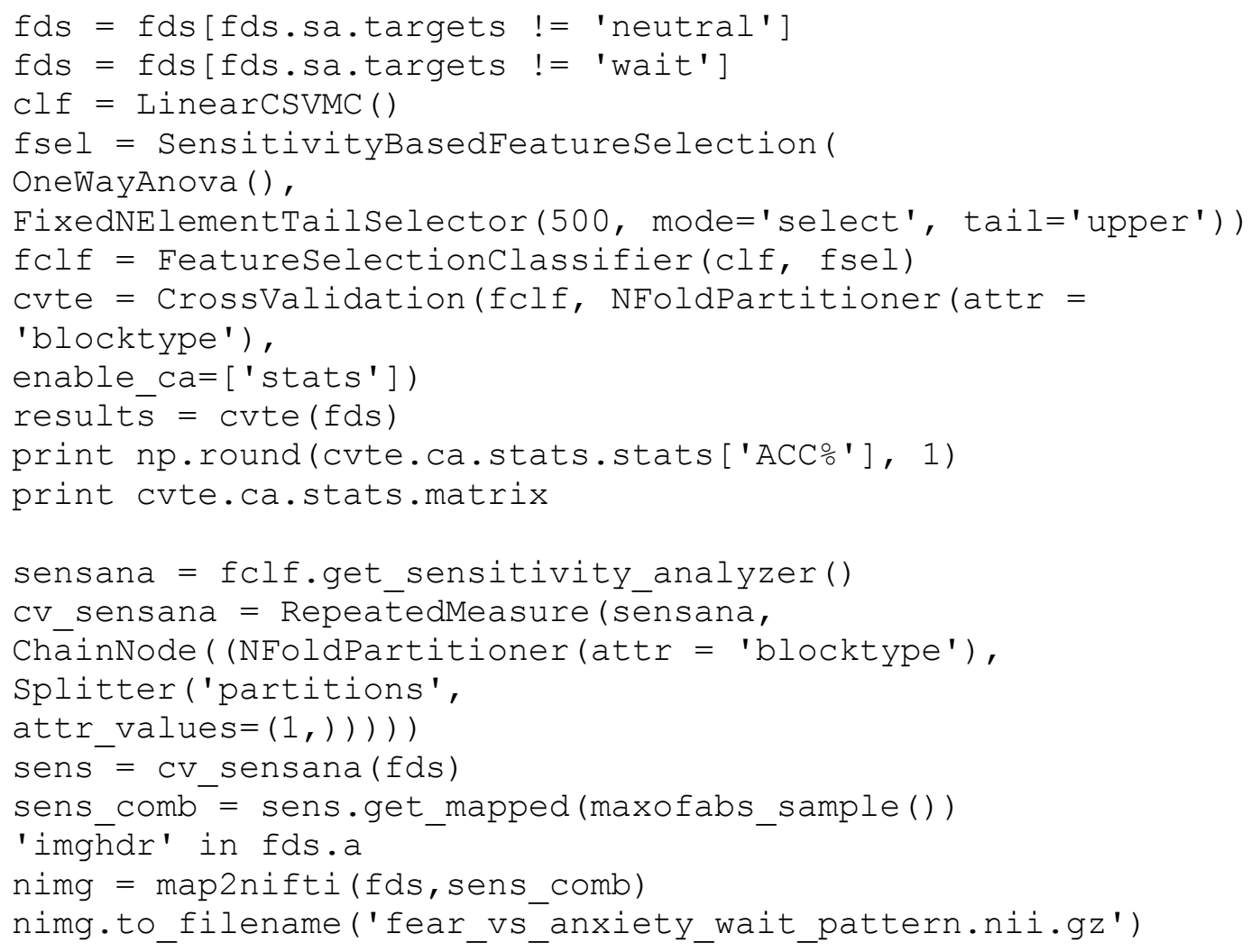




\section{CURRICULUM VITA}

Sajjad Torabian

Current Position

M.Sc. Student, Computer Science, J.B. Speed School of Engineering, University of Louisville, Kentucky, United States

Contact Information

s0tora02@louisville.edu

Research Interests

Computational Cognitive Neuroscience, Artificial Intelligence, Al Safety

Education

M.Sc., Computer Engineering and Computer Science department, University of Louisville, KY, USA

B.Sc., Computer Engineering, Department of Electrical and Computer Engineering, University of Tehran, Tehran, Iran

Academic Experience

Research Assistant at Neurolmaging Laboratory of Cognitive Affective and Motoric Processes, Dept. of Psychological and Brain Sciences, Univ. of Louisville

Honors \& Awards

Merit Scholar Award, University of Louisville, equal to $\$ 14,000$ per year

Ranked 314th among 87,000 applicants in National Universities Entrance Exam, 2009

Publications

S. Torabian, S. HoseinAlipour, A. Mirzargar, and M. Tavakkolian, "Improving the Localization of Humanoid 
Soccer Robots in Specified Fields: A Neural Network Approach"

Computer Skills

Programming Tools and Languages: C, C++, C\#, Java, Python, SQL

Languages

English: Fluent

Persian: Native Language

References

Available upon request 